УДК 621.039

\title{
Underground Research Laboratory in "the Yenisei" Section of the Nizhnekansky Massif of the Krasnoyarsk Region
}

\author{
Igor I. Linge ${ }^{\text {a }}$, Sergey S. Utkin*a, \\ Tatiana A. Kulagina ${ }^{\mathrm{b}}$ and Nikolay N. Trokhov \\ ${ }^{a}$ Nuclear Safety Institute of the RAS \\ 52 B. Tulskaya Str., Moscow, 115191, Russia \\ ${ }^{b}$ Siberian Federal University \\ 79 Svobodny, Krasnoyarsk, 660041, Russia \\ ${ }^{c}$ National Operator for Radioactive Waste Management \\ 49A Pyatnitskaya Str., Moscow, 119017, Russia
}

Received 19.09.2019, received in revised form 10.10.2019, accepted 25.10.2019

The issues of the construction and operation of an underground research laboratory for the purpose of substantiating the long-term safety of the deep radioactive waste disposal facility in the Russian Federation from the perspective of scientific support are considered. The basic principles are stated and the key directions of a long-term program of scientific research, including in an underground laboratory, are justified for assessing and substantiating the safety of an object at all stages of its life cycle.

Keywords: radioactive waste, underground research laboratory, strategic master plan, safety assessment and justification.

Citation: Linge I.I., Utkin S.S., Kulagina T.A., Trokhov N.N. Underground research laboratory in "the Yenisei” section of the Nizhnekansky massif of the Krasnoyarsk Region, J. Sib. Fed. Univ. Eng. technol., 2019, 12(7), 830-841. DOI: 10.17516/1999494X-0183.

(c) Siberian Federal University. All rights reserved

This work is licensed under a Creative Commons Attribution-NonCommercial 4.0 International License (CC BY-NC 4.0).

* Corresponding author E-mail address: linge@ibrae.ac.ru, uss@ibrae.ac.ru 


\title{
Подземная исследовательская лаборатория \\ на участке «Енисейский» Нижнеканского массива \\ Красноярского края
}

\author{
И.И. Линге ${ }^{\mathrm{a}}$, С.С. Уткин ${ }^{\mathrm{a}}$, \\ Т.А. Кулагина ${ }^{\tilde{\sigma}}$, Н.Н. Трохов ${ }^{\text {в }}$ \\ ${ }^{a}$ Институт проблем безопасного развития \\ атомной энергетики РАН \\ Россия, 115191, Москва, ул. Б. Тульская, 52 \\ ${ }^{6}$ Сибирский федеральный университет \\ Россия, 660041, Красноярск, пр. Свободный, 79 \\ ${ }^{6}$ Национальный оператор по обращению \\ с радиоактивными отходами \\ Россия, 119017, Москва, ул. Пятниикая, $49 \mathrm{~A}$
}

Рассмотрены вопросы сооружения и эксплуатации подземной исследовательскойлаборатории для обоснования долговременной безопасности пункта глубинного захоронения радиоактивных отходов в Российской Федеращии с позищии научного сопровождения. Изложены основные принципы и ключевые направления долговременной программы научных исследований, в том числе в подземной лаборатории, для оценки и обоснования безопасности объекта на всех этапах его жизненного ичила.

Ключевые слова: радиоактивные отходы, подземная исследовательская лаборатория, стратегический мастер-план, оценка и обоснование безопасности.

\section{Введение}

В России создана собственная правовая и организационная система обеспечения и регулирования ядерной и радиационной безопасности [1-3], соответствующая международным конвенциям, признанным Российской Федерацией $[4,5]$. Существующая в нашей стране система обращения с радиоактивными отходами (РАО) сформировалась в процессе развития в СССР ядерных технологий и в силу этого имеет ряд характерных особенностей, которые отличают ее от других стран $[6,7]$. Технологии обращения с радиоактивными отходами и труднорастворимыми осадками в хранилищах жидких радиоактивных отходов радиохимических производств описаны в [8-13]. Однако накопленный до настоящего времени опыт обращения с РАО является лишь фундаментом для дальнейших углубленных исследований, целью которых может быть обеспечение высокой надежности и долговечности хранения отходов ядерного топливного цикла.

В 2018 г. на участке «Енисейский» недалеко от г. Железногорска начаты работы по созданию подземной исследовательской лаборатории (далее - ПИЛ). Это будет единственная в России и одна из порядка 30 существующих в мире на разных стадиях своего жизненного цикла подземных лабораторий (активно эксплуатируются около половины), создаваемых для изучения возможности и обоснования долгосрочной безопасности геологического захоронения радиоактивных отходов [14-16]. 
В работе [17] представлен план изучения влияния биогенных и биогенно-опосредованных процессов на стабильность барьеров безопасности и миграцию компонентов РАО в ближней зоне пункта захоронения в условиях подземной исследовательской лаборатории в Нижнеканском массиве (НКМ) Красноярского края. Также проведена оценка результатов более чем 30-летних исследований биогенных процессов в зарубежных лабораториях, определен перечень наиболее важных из них для условий захоронения в пунктах глубинного захоронения РАО (ПГЗРО) НКМ, включая газообразование, изменение материалов барьера (сталь, цемент, глина, скальный массив), увеличение мобильности радионуклидов в составе биогенных комплексов, коллоидов и псевдоколлоидов, изменение геохимических параметров среды.

Создание пунктов глубинного захоронения РАО позиционировано в мире и МАГАТЭ как чрезвычайно сложная, мультидисциплинарная проблема, требующая длительных и масштабных усилий по разработке научно-технических основ и инструментария для оценки и обоснования долговременной безопасности, а также неизбежной оптимизации характеристик объекта [18-23]. ПГЗРО будет представлять собой сооружение, состоящее из системы тоннелей и скважин, для размещения подготовленных к окончательной изоляции РАО. Участок «Енисейский» Нижнеканского массива Красноярского края рассматривается с начала 90-х гг. прошлого века [24], практические работы уже ведутся.

Как и во многих подобных проектах, требующих максимальной надежности, для всестороннего анализа и обоснования безопасности глубинного захоронения долгоживущих РАО на начальном этапе на объекте планируется создание ПИЛ, в которой в реальных условиях предполагается провести принципиально важный и трудозатратный объем научно-исследовательских работ [17].

В последние годы во ФГАОУ ВО «Сибирский федеральный университет» (СФУ) накоплен опыт обращения с особо опасными отходами, в том числе и радиоактивными, на базе кавитационной технологии, построенной с использованием эффектов гидродинамической кавитации [25-30].

Кавитационные технологии - интенсивное механотермическое воздействие на молекулярном уровне на полидисперсные среды в результате реализации эффектов гидродинамической кавитации (активации вещества); использование модифицированных в результате кавитационной обработки физико-химических свойств воды (возникновение свободных водородных связей в результате ее деструкции, изменение кислородосодержания, рН среды, электропроводности, окислительно-восстановительного потенциала и др.); интенсивное турбулентное микроперемешивание и др. Кавитационную технологию можно рассматривать как новый метод получения наноматериалов или наноструктур и представить его в виде комбинации уже известных (например, механохимический синтез - ударно-волновой - высокотемпературный синтез), но обладающих рядом преимуществ (простота реализации, энергоэффективность, экобезопасность и многое другое).

Использование гидродинамических и теплофизических эффектов кавитации (кавитационной технологии) способствует механотермолизу структуры воды на молекулярном уровне с появлением свободных водородных связей, диспергации и гомогенизации с образованием устойчивых эмульсий, суспензий и смесей, в конечном итоге имеющим перспективу для усовершенствования и интенсификации технологических процессов в различных отраслях произ- 
водства, основанных на интенсивной обработке полидисперсных систем. Вследствие чрезвычайной сложности физических процессов, происходящих при кавитации, механизм действия последней трудно поддается теоретическому исследованию. Важную роль в данном случае играет эксперимент, при этом большое значение имеют исследования масштабного эффекта при кавитации [31].

\section{Соглашение о научном, образовательном и техническом сотрудничестве}

Успешная реализация данного проекта практически невозможна без пристального внимания со стороны научно-технической общественности. Именно это обстоятельство стало мотивом для подготовки соглашения о сотрудничестве между СФУ, ИБРАЭ РАН и будущим оператором исследовательской лаборатории, которое было подписано 3 октября 2019 г. непосредственно на площадке строительства (рис. 1). Вторым мотивом явилась потребность в специалистах с достаточно уникальной комбинацией специальностей, которые ранее нигде в России целевым образом не готовились.

Кратко об основных участниках соглашения. Тематика промышленной и экологической безопасности в целом и обращение с радиоактивными отходами исследуются в практическом плане на кафедре техносферной и экологической безопасности ФГАОУ ВО «Сибирский федеральный университет». При этом изучение и преподавание дисциплин, которые могут быть

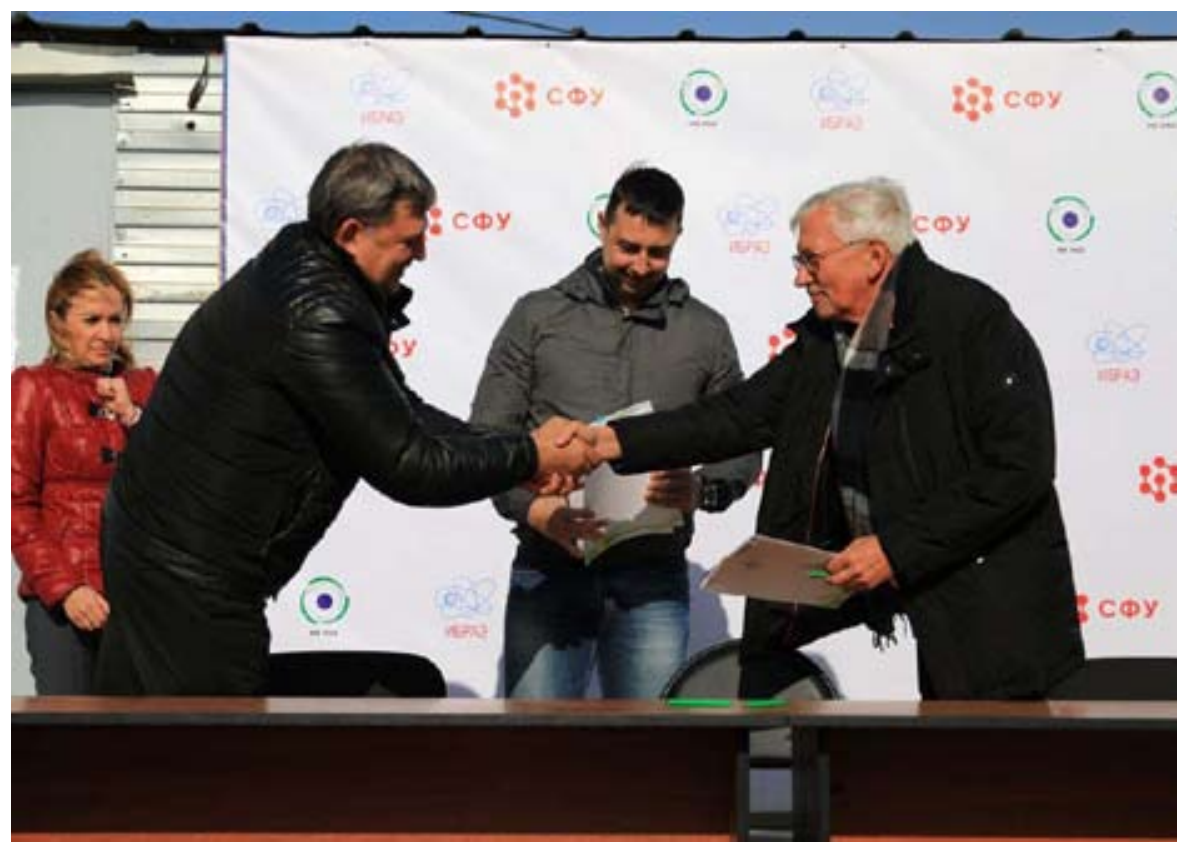

Рис. 1. Подписание соглашения о научном, образовательном и техническом сотрудничестве в области исследований обращения с радиоактивными отходами между ИБРАЭ РАН (справа - И.И. Линге, заместитель директора), ФГУП «НО РАО» (слева - Н.Н. Трохов, заместитель генерального директора) и СФУ (в центре - М.В. Румянцев, врио ректора)

Fig. 1. The signing of an agreement on scientific, educational and technical cooperation in the field of research on radioactive waste management between the IBRAE RAS (on the right - I.I. Linge, deputy director), FSUE "NO RAO" (on the left - N.N. Trokhov, deputy general Director) and SFU (in the center - M.V. Rumyantsev, interim rector)

$$
-833-
$$


востребованы ПИЛ, уже ведутся в рамках нескольких образовательных программ и специальностей, но также, очевидно, есть потребность и в создании новых.

ФГУП «Национальный оператор по захоронению радиоактивных отходов» - специально созданная в 2012 г. организация. Решение по ее созданию было принято Правительством России на основании Федерального закона № 190 Ф3 «Об обращении с радиоактивными отходами». Филиал «Железногорский» был создан на базе подразделений ФГУП «ГХК», на протяжении нескольких десятилетий осуществлявших захоронение ЖРО в подземных пластах-коллекторах [32]. В соответствии с тем же законом все пункты захоронения были сконцентрированы в одной организации и отделены от организаций, в результате деятельности которых РАО образуются, поскольку только такая мера полностью исключает ситуации, когда производственные задачи по эксплуатации могут решаться в ущерб безопасности захоронения РАО. Эксплуатация ПГЗ ЖРО в настоящее время продолжается. Одновременно ведутся работы по проработке вопросов безопасного закрытия этого полигона [33].

ИБРАЭ РАН был создан в 1988 г. решением Правительства СССР в целях расширения и углубления фундаментальных исследований, создающих основу для обеспечения безопасности атомной энергетики. В последние десять лет специалистами института был внесен существенный вклад в выработку мер по отдельным сложным объектам ядерного наследия и разработано несколько системных документов, в том числе связанных с реализацией ФЦП ЯРБ, созданием ЕГС РАО и т.д. [34].

\section{Историческая справка}

В период 1990-2015 гг. в Российской Федерации в рамках создания ПГЗРО был реализован комплекс изыскательских и проектных работ. До 2007 г. выполнение работ сопровождалось их более-менее регулярным рассмотрением в научном сообществе $[35,36]$. Условия реализации работ по проекту в 2008-2013 гг., напротив, не только не предусматривали необходимости, но и исключали возможность привлечения широкого круга специалистов к экспертизе и оценке качества проектных решений. В 2012 г. было принято решение о месте размещения объекта на участке «Енисейский». Оно также не сопровождалось публикацией исчерпывающего обоснования.

В последние годы ситуация принципиально изменилась. В июле 2015 г. в г. Железногорске состоялись общественные слушания по теме «Материалы обоснования лицензии на размещение и сооружение не относящегося к ядерным установкам пункта хранения РАО, создаваемого в соответствии с проектной документацией на строительство объектов окончательной изоляции РАО (Красноярский край, Нижнеканский массив) в составе подземной исследовательской лаборатории (включая материалы оценки воздействия на окружающую среду)». К 2016 г. ФГУП «НО РАО» был разработан ключевой документ по обоснованию безопасности с учетом результатов этих слушаний. Уже весной 2016 г. данные материалы были представлены на секции НТС № 10 Госкорпорации Росатом, а затем поданы в Ростехнадзор для получения соответствующей лицензии. В обоих случаях по итогам рассмотрения были сформированы развернутые замечания. В этой ситуации было признано необходимым:

- определение более гибкой стратегии, в рамках которой будет предусмотрено внесение корректировок в проект и отнесение решения ряда значимых вопросов по компоновке, 
безопасности и сооружению объекта на временной период исследований в ПИЛ (при этом ряд исследований будет выполняться и вне ПИЛ);

- формирование особых условий организации НИР и НИОКР, включая обмен данными, с целью обеспечения преемственности работ, единообразия методов и аналитической основы.

Отметим, что это вполне соответствует международной практике, которая при вполне четких стратегических установках создания ПГЗРО и вехах по принятию решений допускает значительную вариативность в плане конкретного воплощения тех или иных работ.

В 2016 г. с учетом того, что требования к объему и направленности исследований, необходимых для принятия решений (масштаб, наукоемкость, разнородность и взаимосвязанность), традиционно таковы, что ни одна организация в отдельности ни в одной стране не обладает всеми необходимыми компетенциями, директором по государственной политике в области РАО, ОЯТ и ВЭ ЯРОО Госкорпорации «Росатом» было признано целесообразным консолидировать вопросы научно-технического сопровождения создания ПГЗРО в формате стратегического мастер-плана (СМП НКМ). Подобная методология была ранее успешно применена к таким комплексным и долговременным проектам, как утилизация объектов атомного подводного флота на северо-западе России [37] и переводу в безопасное состояние Теченского каскада водоемов ФГУП «ПО «Маяк» [38].

К началу 2018 г. СМП НКМ был разработан Стратегический мастер-план исследований в обоснование безопасности сооружения, эксплуатации и закрытии пункта глубинного захоронения радиоактивных отходов [39]. В этот же период была разработана и утверждена генеральным директором Госкорпорации «Росатом» «Стратегия создания ПГЗРО» [40]. Отметим несколько принципиальных моментов стратегии. Это четкая продолжительность первых двух фаз и ограничение минимальной продолжительности третьей:

- фаза № 1 «Подготовительные работы по созданию ПИЛ»- до 5 лет (2017-2021 гг.);

- фаза № 2 «Сооружение демонстрационного центра и основных сооружений ПИЛ»-до 5 лет;

- фаза № 3 «Эксплуатация и развитие ПИЛ» - от 5 лет и более.

Это означает, что при необходимости весь комплекс исследований будет продолжен, а следующая фаза (№ 4 «Принятие решения о возможности создания ПГзРО. Лицензирование деятельности по сооружению ПГЗРО. Реализация мероприятий по сооружению 1-й очереди ПГЗРО». Длительность - от 5 лет и более) начнется позже. В табл. приведены основные итоги первого этапа взаимодействия с заинтересованными сторонами.

\section{Первоочередные задачи сотрудничества}

К началу 2020 г. можно констатировать наличие капитального фундамента для совместных работ. Это планы сооружения объекта и наработки по облику и составу экспериментов в ПИЛ, это потребность НО РАО и исследовательской программы ИБРАЭ РАН в высококвалифицированных кадрах, готовых и работать на объекте, и участвовать в обязательном для такого рода проектов международном сотрудничестве, это, наконец, уже упомянутые обязательства по взаимодействию с общественностью. СФУ, в частности, считает безусловно необходимым активное и долговременное участие в реализуемом в регионе исследовательском проекте миро- 
Таблица

\begin{tabular}{|c|c|c|}
\hline № & Ключевой результат «Стратегии...» & Что выполнено \\
\hline 1 & $\begin{array}{l}\text { Организован выпуск специального научно- } \\
\text { технического журнала «Радиоактивные } \\
\text { отходы» для размещения основных данных по } \\
\text { безопасности объекта }\end{array}$ & $\begin{array}{l}\text { Журнал создан. За два года в нем опубликовано } \\
\text { более } 20 \text { научных статей по вопросам } \\
\text { подземной исследовательской лаборатории и } \\
\text { геологического захоронения РАО }\end{array}$ \\
\hline 2 & Отчеты по реализации проекта - ежегодно & $\begin{array}{l}\text { Материалы по реализации проекта } \\
\text { публикуются регулярно, в том числе на сайтах } \\
\text { НО РАО, ФЦП ЯРБ [41] }\end{array}$ \\
\hline 3 & $\begin{array}{l}\text { Обсуждение отчета с общественностью, в том } \\
\text { числе - Красноярска и/или Железногорска }\end{array}$ & $\begin{array}{l}\text { Одно из таких обсуждений состоялось в } \\
\text { г. Железногорске } 3 \text { октября } 2019 \text { г. }\end{array}$ \\
\hline 4 & \begin{tabular}{llll} 
Информация по реализации & \multicolumn{2}{c}{ Стратегии } \\
представляется на очередном & Совещании \\
высоких договаривающихся & сторон \\
Объединенной конвенции & & \\
\end{tabular} & $\begin{array}{l}\text { Информация о разработке была доложена на } \\
6 \text {-м совещании (2018 г., МАГАТЭ) и готовится } \\
\text { к докладу на 7-м (2021 г., МАГАТЭ) }\end{array}$ \\
\hline 5 & $\begin{array}{l}\text { Проведение 1-й Международной конференции } \\
\text { по проблематике создания и обоснования } \\
\text { безопасности пункта захоронения РАО } \\
\text { глубинного типа в Нижнеканском массиве }\end{array}$ & в 2021 г. \\
\hline
\end{tabular}

вого уровня, включая развитие образовательных программ заинтересованных кафедр и непосредственное участие специалистов СФУ в научных исследованиях.

Кратко рассмотрим первоочередные задачи сотрудничества на ближайшие два года. Первую из них, по-видимому, можно считать решенной. Предложено и согласовано название подземной лаборатории - ERLIK (Exploratory Rock Laboratory in Krasnoyarsk region). Его мифологическое происхождение от бога подземного мира народов, живших на этих территориях, очень созвучно первоочередным и долгосрочным целям работ - выбрать способы и средства для создания объекта, в минимальной степени нарушающего целостность горного массива, а затем обеспечить сохранение этого состояния на бесконечно большие времена.

В сфере научно-образовательных программ СФУ уже в 2020 г. планирует начать подготовку кадров для ПИЛ, в том числе по направлению сопровождения горнопроходческих работ и составу экспериментов ПИЛ [42] (рис. 2). В период 2020-2023 гг. представляется важным иметь набор специальных программ экспериментальных исследований по всем установкам в ПИЛ, в том числе предусматривающих стажировку в ведущих научных центрах России и за рубежом.

В конце 2020 г. ФГУП «НО РАО» планирует начало проходки вертикальных стволов. Проходка будет сопровождаться беспрецедентно детальным описанием получаемых данных. Можно предположить, что участки недр, прилегающие к вертикальным стволам ПИЛ, будут наиболее исследованными в России и мире. Представляется важным участие специалистов СФУ в этой работе с одновременным формированием образовательного материала и фундаментального труда - «Геологическое строение участка «Енисейский» - результаты проходки вертикальных стволов».

В конце 2020 г. ИБРАЭ РАН планирует завершить монографию, дающую представление об основных причинах выбора участка «Енисейский» для сооружения объекта.

$$
-836-
$$




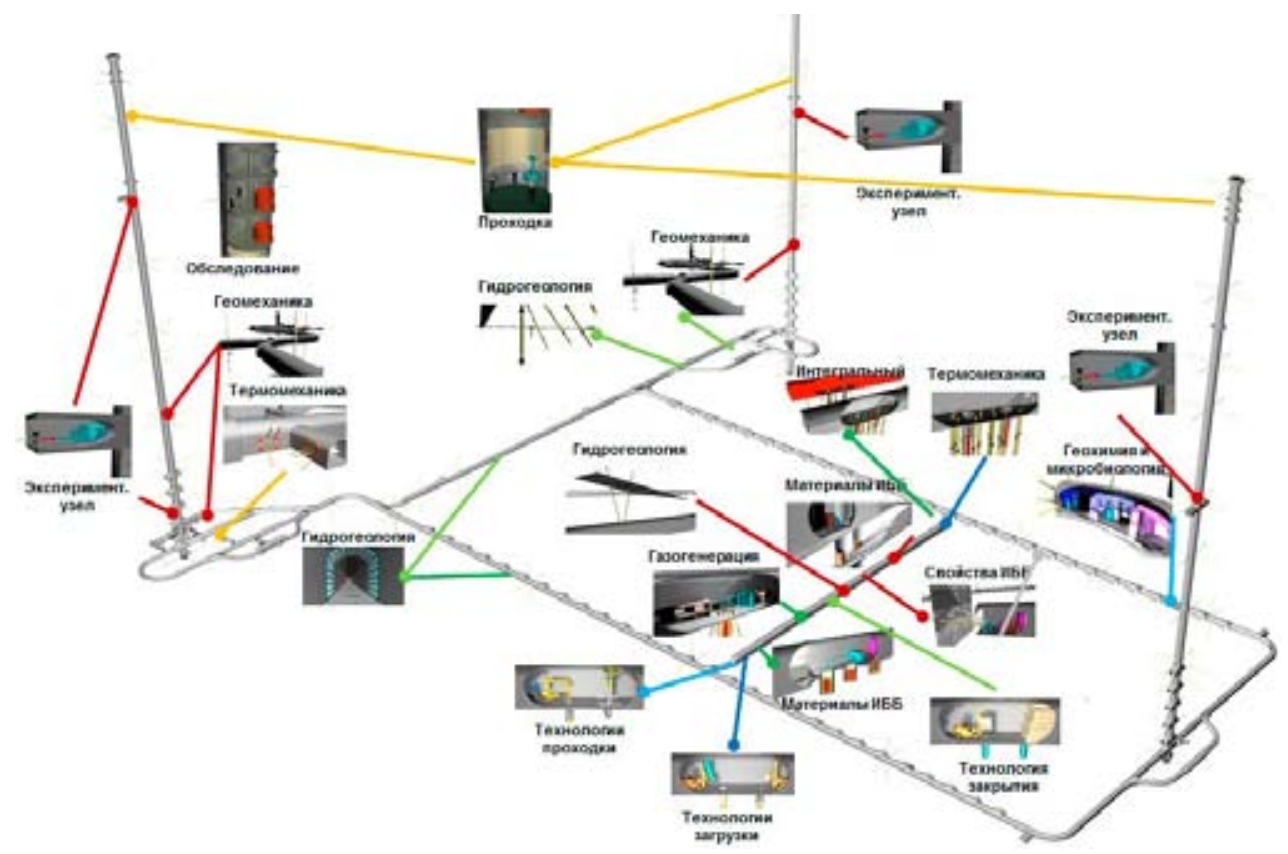

Рис. 2. Предварительная схема ПИЛ

Fig. 2. The preliminary scheme of ERLIK

\section{Заключение}

Организация в 2021 г. на Красноярской земле международной научной конференции, посвященной вопросам обоснования долговременной безопасности геологического захоронения РАО, завершит фазу № 1 «Стратегия создания ПГЗРО» и позволит продолжить формирование доверительного отношения у большинства жителей региона к проекту создания ПИЛ в целом и началу горнопроходческих работ в частности.

\section{Благодарность}

Исследование выполнено при финансовой поддержке РФФИ и Правительства Красноярского края в рамках научных проектов № 18-48-242001 «Теплофизические и гидродинамические особенности кинетики смесеобразования при иммобилизации радиоактивных отходов в цементную матрицу с использованием эффектов кавитации», № 18-41-242004 «Теоретические основы кондиционирования вод питьевого назначения на базе эффектов гидродинамической кавитации».

\section{Список литературы}

[1] Об использовании атомной энергии. Федеральный закон от 21.11.95 № 170-FZ (ред. от 02.07.2013 с изменениями, вступившими в силу 02.09.2013) [On nuclear energy use. Federal law dated November 21, 1995, No. 170-FZ (revised on July 2, 2013 with amendments which entered into force on September 2, 2013 (in Russian)]

[2] Безопасность России. Правовые, сочиально-экономические и научно-технические aспекты. Регулирование ядерной и радиационной безопасности; кол. авт. М.: МГОФ «Знание», 
НТЦ ЯРБ, 2003. 400 c. [Security of Russia. Legal, socio-economic and scientific-technical aspects. Regulation of nuclear and radiation safety; count author M.: MGOF “Znaniye”, STC NRS, 2003. 400 p. (in Russian)]

[3] Санитарные правила обращения с радиоактивными отходами (СПОРО-2002). СП 2.6.6.1168-02. СПб: Деан, 2003. 64 с. [Sanitary Regulations of Radioactive Waste Management (SRRWM - 2002) SR 2.6.6.1168-02. St. Petersburg, Dean, 2003, 64 p. (in Russian)]

[4] Объединенная конвенция о безопасности обращения с отработавшим топливом и безопасности обращения с радиоактивными отходами. Вена, 5 сентября 1997 года. Конвенция вступила в силу для России 19.04.2006. Режим доступа: http://www.bellona.ru/Casefiles/ vienna97 [Joint Convention on the Safety of Spent Fuel Management and the Safety of Radioactive Waste Management. Vienna, September 5, 1997. The Convention entered into force for Russia on April 19, 2006. Access: http://www.bellona.ru/Casefiles/vienna97 (in Russian)]

[5] Конвениия о ядерной безопасности. Вена, 17 июня 1994 года. Конвенция вступила в силу для России 24.10.1996. Режим доступа: http://www.bellona.ru/Casefiles-/vienna94. [Convention on Nuclear Safety. Vienna, June 17, 1994. The Convention entered into force for Russia on 10.24.1996. Access: http://www.bellona.ru/Casefiles-/vienna94. (in Russian)]

[6] Ключников А.А., Пазухин Э.М., Шигера Ю.М., Шигера В.Ю. Радиоактивные отходы АЭС и методы обращения с ними; ред. Ю.М. Шигера. Киев: Чернобыль, 2005. 496 с. [Kliuchnikov A.А., Pazukhin E.M., Shigera Iu.M. \& Shigera V.Iu. Radioactive waste of NPP and treatment methods. Kiev, Institut problem bezopasnosti AES NAN Ukrainy, 2005, 487 p. (in Russian)]

[7] Лебедев В.М. Ядерный топливный иикл. М.: Энергоатомиздат, 2005. 305 с. [Lebedev V.M. Nuclear fuel cycle. Moscow, Energoatomizdat, 2005, 305 (in Russian)]

[8] Волков В.Г., Чесноков А.С. Радиоактивные отходы: хранение и переработка. Промышленные ведомости, 2011, 11-12 [Volkov V.G. \& Chesnokov A.S. Radioactive waste: storage and processing. Promyshlennye vedomosti, 2011, 11, 12 (in Russian)]

[9] Милютин В.В., Гелис В.М. Современные методы очистки жидких радиоактивных отходов и радиоактивно-загрязненных природных вод. М.: ИФХЭ РАН, 2011 [Milyutin V.V., Gelis V.M. Modern methods of purification of liquid radioactive waste and contaminated natural waters. M.: IEPhE RAS, 2011 (in Russian)]

[10] Кулагина Т.А., Кулагин В.А., Матюшенко А.И. Техносферная безопасность в ядерной энергетике. Красноярск: Гротеск, СФУ, 2014.286 c. [Kulagina T.A., Kulagin V.A., Matyushenko A.I. Technosphere safety in nuclear power. Krasnoyarsk: Grotesk, Siberian Federal University, 2014. 286 p. (in Russian)]

[11] Кулагина Т.А., Козин О.А., Матюшенко А.И. Экологическая безопасность техносферHblх объектов. Красноярск: Гротеск, 2015. 323 с. [ Kulagina T.A., Kozin O.A. \& Matiushenko A.I. Environmental safety of technospheric objects. Krasnoyarsk, Grotesk, 2015, 323 p. (in Russian)]

[12] Кулагин В.А., Кулагина Т.А., Матюшенко А.И. Переработка отработавшего ядерного топлива и обращение с радиоактивными отходами. Журнал СФУ. Техника и технологии, 2013, 6(2), 123-149 [Kulagin V.A., Kulagina T.A., Matyushenko A.I. Spent nuclear fuel reprocessing and radioactive waste management. Sib. Fed. Univ. Eng. technol., 2013, 6(2), 123-149 (in Russian)]

[13] Кулагина Т.А., Козин О.А., Попков В.А. Обращение с радиоактивными отходами. Красноярск: Гротеск; СФУ, 2018. 183 с. [Kulagina T.A., Kozin O.A., Popkov V.A. Radioactive waste management. Krasnoyarsk: Grotesk; Siberian Federal University, 2018. 183 p. (in Russian)] 
[14] Цебаковская Н.С. и др. Обзор зарубежных практик захоронения ОЯТ и РАО; ред. И.И. Линге, Ю.Д. Поляков М.: Комтехпринт, 2015. 208 c. [Tsebakovskaya N.S. et al. Review offoreign practices for the disposal of spent nuclear fuel and radioactive waste; ed. I.I. Linge, Yu.D. Polyakov. M.: Komtekhprint, 2015. 208 p. (in Russian)]

[15] Цебаковская Н.С., Уткин С.С., Линге И.И., Пронь И.А. Зарубежные проекты захоронения ОЯТ И РАО. Часть І. Актуальное состояние проектов создания пунктов глубинного геологического захоронения в европейских странах. Препринт ИБРАЭ, № IBRAE-2017-03. М.: ИБРАЭ PAH, 2017. 35 c. [Tsebakovskaya N.S., Utkin S.S., Linge I.I., Pron I.A. Foreign SNF and RW disposal projects. Part I. Current status of projects for the creation of deep geological burial sites in European countries. Preprint IBRAE, No. IBRAE-2017-03. M.: IBRAE RAS, 2017. 35 p. (in Russian)]

[16] Цебаковская Н.С., Уткин С.С., Коновалов В.Ю. Зарубежные проекты захоронения ОЯТ И РАО. Часть ІІ. Актуальное состояние проектов создания пунктов глубинного геологического захоронения в США, КАНАДЕ и странах Азиатского региона. Препринт ИБРАЭ № IBRAE-2017-04. М.: ИБРАЭ РАН, 2017. 41 c. [Tsebakovskaya N.S., Utkin S.S., Konovalov V.Yu. Foreign SNF and RW disposal projects. Part II Current status of projects for the creation of deep geological burial sites in the United States, CANADA and the countries of the Asian region. IBRAE Preprint No. IBRAE-2017-04. M.: IBRAE RAS, 2017. 41 p. (in Russian)]

[17] Сафонов А.В., Болдырев К.А. Исследование биогенных процессов в ПИЛ ПГЗРО в Нижнеканском массиве. Радиоактивные отходы, 2019, 2(7), 92-100; DOI: 10.25283/2587-97072019-2-92-100 [Safonov A.V., Boldyrev K.A. URL in the Nizhnekanskiy Massif: Studying Biogenic Processes under HLW Disposal Project, Radioactive Waste, 2019, 2(7), 92-100; DOI: 10.25283/25879707-2019-2-92-100 (In Russian)].

[18] IAEA-Tecdoc-1243. The use of scientific and technical results from underground research laboratory investigations for the geological disposal of radioactive waste. Vienna, 2001.

[19] Underground Research Laboratories (URL), NEA/RWM/R(2013)2. 2013. [Electronic resources] Access: https://www.oecd-nea.org/rwm/reports/2013/78122-rwm-url-brochure.pdf - Free. Paris, France: OECD.

[20] Features, Events and Processes (FEPs) for Geologic Disposal of Radioactive Waste, NEA International FEP Database: Version 2.1. - NEA OECD, 2006.

[21] Захоронение радиоактивных отходов, Конкретные требования безопасности № SSR5, Нормы МАГАТЭ по безопасности, МАГАТЭ, Вена, 2011. [Radioactive Waste Disposal, Specific Safety Requirements No. SSR-5, IAEA Safety Standards, IAEA, Vienna, 2011 (in Russian)]

[22] Geological Disposal Facilities for Radioactive Waste, Specific Safety Guide No. SSG-14, IAEA Safety Standards, IAEA, Vienna, 2011.

[23] The Safety Case and Safety Assessment for the Disposal of Radioactive Waste, Specific Safety Guide No. SSG-23, IAEA Safety Standards. International Atomic Energy Agency, Vienna, Austria, 2012.

[24] Подземная исследовательская лаборатория в Нижнеканском массиве. ФГУП «Национальный оператор по обращению с радиоактивными отходами». Режим доступа: http://www. norao.ru/about/underground/ [Underground research laboratory in the Nizhnekansky massif. National Operator for Radioactive Waste Management. Access: http://www.norao.ru/about/underground/ (in Russian)] 
[25] Ивченко В.М., Кулагин В.А., Немчин А.Ф. Кавитационная технология; ред. акад. Г.В. Логвинович. Красноярск: Изд-во КГУ, 1990. 200 с. [Ivchenko V.M., Kulagin V.A. \& Nemchin A.F. Cavitation technology. Krasnoyarsk, KGU, 1990, 200 p. (in Russian)]

[26] Кулагина Т.А., Кулагин В.А., Москвичев В.В., Попков В.А. Применение кавитационной технологии в процессах обращения с отработавшим ядерным топливом, Экология и промышленность России, 2016, 20(10), 4-10; DOI: 10.18412/1816-0395-2016-10-4-10 [Kulagina T.A., Kulagin V.A., Moskvichev V.V., Popkov V.A. The Use of Cavitation Technology in the Treatment of Spent Nuclear Fuel Processes, Ecology and industry of Russia, 2016, 20(10), 4-10: DOI: 10.18412/18160395-2016-10-4-10 (in Russian)]

[27] Kulagina T.A., Kulagin V.A., Popkov V.A. Compounding of spent nuclear fuel, J. Sib. Fed. Univ. Eng. technol. 2016, 9(2), 280-295, DOI: 10.17516/1999-494X-2016-9-2-280-295.

[28] Кулагина Т.А., Попков В.А. Подготовка радиоактивных отходов к длительному хранению (захоронению) с помощью цементных компаундов. Журнал СФУ. Техника и технологии, 2015, 8(7), 917-927, DOI: 10.17516/1999-494X-2015-8-7-917-927. [Kulagina T.A., Popkov V.A. Preparation of radioactive waste for long-term storage (burial) using cement compounds. Sib. Fed. Univ. Eng. technol., 2015, 8(7), 917-927, DOI: 10.17516/1999-494X-2015-87-917-927 (in Russian)]

[29] Kulagina T.A., Kulagin V.A., Popkov V.A. Envionmental Effects of Cavitation Technology for Radioactive Waste Management. Chemical and Petroleum Engineering, 2018, 53(11-12), 738-744.

[30] Kulagina T., Kulagin V., Nikiforova E., Prikhodov D., Shimanskiy A. and Li F. Inclusion of liquid radioactive waste into a cement compound with an additive of multilayer carbon nanotubes. IOP Conf. Series: Earth and Environmental Science 227 (2019) 052030; DOI: 10.1088/17551315/227/5/052030

[31] Кулагин В.А., Москвичев В.В., Махутов Н.А., Маркович Д.М., Шокин Ю.И. Физическое и математическое моделирование в области гидродинамики больших скоростей на экспериментальной базе Красноярской ГЭС. Вестник Российской академии наук, 2016, 86(6), 454-465 [Kulagin V.A., Moskvichev V.V., Makhutov N.A., Markovich D.M. and Shokin Yu.I. Physical and Mathematical Modeling in the Field of High-Velocity Hydrodynamics in the Experimental Base of the Krasnoyarsk Hydroelectric Plant. Herald of the Russian Academy of Sciences, 2016, 86(6), 454-465. DOI: 10.1134/S1019331616060034 (in Russian)]

[32] Рыбальченко А.И. и др. Глубинное захоронение жидких радиоактивных отходов. М.: ИздАТ, 1994. 256 c. [Rybalchenko A.I. et al. Deep burial of liquid radioactive waste. M.: Publishing House, 1994. 256 p. (in Russian)]

[33] Дорофеев А.Н, Савельева Е.А., Уткин С.С. и др. Эволюция обоснования долговременной безопасности ПГЗ ЖРО. Радиоактивные отходы, 2017, 1, 54-63 [Dorofeev A.N., Savelyeva E.A., Utkin S.S. et al. Evolution of the rationale for the long-term safety of the PHZ LRW. Radioactive waste, 2017, 1, 54-63 (in Russian)]

[34] Большов Л.А., Линге И.И., Уткин С.С., Ведерникова М.В. К 30-летию ИБРАЭ РАН: основные итоги деятельности в области обращения с РАО. Радиоактивные отxоды, 2018, 2(3), 7-15 [Bolshov L.A., Linge I.I., Utkin S.S., Vedernikova M.V. On the 30th anniversary of the IBRAE RAS: the main results of activities in the field of radioactive waste management. Radioactive waste, 2018, 2(3), 7-15 (in Russian)] 
[35] Материалы Координационного научно-технического совета по научному сопровождению проектирования и строительства завода РТ-2 на ГХК «Исследования гранитоидов Нижнеканского массива для захоронения РАО». Железногорск, Санкт-Петербург, 1999. 181 с. [Materials of the Coordinating Scientific and Technical Council for the scientific support of the design and construction of the RT-2 plant at the Mining and Processing Complex "Research on granitoids of the Nizhnekansky massiffor RW disposal” Zheleznogorsk, St. Petersburg, 1999. 181 p. (in Russian)]

[36] Труды Радиевого института им. В.Г. Хлопина. Т. ХІ. Санкт-Петербург, 2006. Режим доступа: http://www.khlopin.ru/?page_id=194 [Proceedings of the Radium Institute. V.G. Khlopin. T. XI. St. Petersburg, 2006. Access: http://www.khlopin.ru/?page_id=194 (in Russian)]

[37] О Стратегическом мастер-плане утилизации и экологической реабилитации выведенных из эксплуатации объектов атомного флота и обеспечивающей инфраструктуры в Северо-западном регионе России. Приказ Росатома от 26.12.2007 № 686 [On the Strategic Master Plan for the Utilization and Environmental Remediation of Decommissioned Nuclear Facilities and Supporting Infrastructure in the Northwest Region of Russia. Rosatom Order of December 26, 2007 № 686 (in Russian)]

[38] Стратегический мастер-план решения проблем Теченского каскада водоемов ФГУП «ПО «Маяк». ИБРАЭ РАН и др. Утвержден генеральным директором Госкорпорации «Росатом» 15.02.2016 [Strategic master plan for solving the problems of the Techen cascade of reservoirs of FSUE PA Mayak. IBRAE RAS and others. Approved by the General Director of the State Atomic Energy Corporation Rosatom 02/15/2016 (in Russian)]

[39] Дорофеев А.Н., Большов Л.А., Линге И.И., Уткин С.С., Савельева Е.А. Стратегический мастер-план исследований в обоснование безопасности сооружения, эксплуатации и закрытия пункта глубинного захоронения радиоактивных отходов. Paдиоактивные oтxoды, 2017, 1. 32-41 [Dorofeev A.N., Bolshov L.A., Linge I.I., Utkin S.S., Savelyeva E.A. Strategic master plan for research to justify the safety of the construction, operation and closure of the deep radioactive waste disposal facility. Radioactive waste, 2017, 1, 32-41 (in Russian)]

[40] Стратегия создания пункта глубинного захоронения радиоактивных отходов. Paдиоактивные отходы, 2018, 3, 114-120 [Strategy for the establishment of a deep radioactive waste disposal facility. Radioactive waste, 2018, 3, 114-120 (in Russian)]

[41] Федеральная целевая программа «Обеспечение ядерной и радиационной безопасности на 2016-2020 годы и на период до 2030 года». Режим доступа: http://фцп-ярб2030.pф [Federal Target Program "Ensuring Nuclear and Radiation Safety for 2016-2020 and for the Period Until 2030”. Access: http://фцп-ярб2030.pф (in Russian)] http://фцп-ярб2030.pф

[42] Решение секции № 1 «Экологическая и радиационная безопасность пунктов долговременного хранения, консервации и захоронения РАО» НТС № 10 Госкорпорации «Росатом» по вопросу «Программа проведения исследований в подземной исследовательской лаборатории (ПИЛ) на Нижнеканском массиве для подтверждения проектных параметров безопасности подземного захоронения РАО классов 1 и 2». 06.04.2016 [Decision of section No. 1 "Ecological and radiation safety of RW long-term storage, conservation and disposal facilities" of NTS No. 10 of Rosatom State Corporation on the subject "Research program at the underground research laboratory (SIL) at the Nizhnekansky massif to confirm the design safety parameters of the underground RW disposal classes 1 and 2.” 04/06/2016 (in Russian)].

$$
-841-
$$

